\title{
JUdiCIALIZAÇÃO, POLICY E MODELOS FORMAIS EXPLICATIVOS: UMA PROPOSTA PARA COMPREENDER AS DECISÕES JUDICIAIS EM MATÉRIA DE POLÍTICAS PÚBLICAS
}

\author{
Michelle FERNANDEZ* \\ José Mário Wanderley GOMES NETO**
}

\begin{abstract}
RESUMO: O presente artigo tem como objetivo apresentar uma proposta de análise da atuação do Poder Judiciário nas políticas públicas. Para tanto, pontuamos os diferentes modelos de análise encontrados na literatura que tratam de explicar a atuação do judiciário, e apresentamos os possíveis locus de atuação deste ator político no ciclo de políticas públicas. Trataremos, portanto, de indicar caminhos para responder à seguinte questão: como compreender melhor quais os fatores que influenciam os membros do Poder Judiciário em suas decisões seletivas quanto à interferência - ou não - nas políticas públicas governamentais?
\end{abstract}

PALAVRAS-CHAVE: Poder judiciário. Políticas públicas. Judicialização da política. Modelos explicativos.

\section{Introdução}

[...]. É firme o entendimento deste Tribunal de que o Poder Judiciário pode, sem que fique configurada violação ao princípio da separação dos Poderes, determinar a implementação de políticas públicas [...]. Ministro Luiz Edson Fachin (STF) ARE 903241 AgR, julgado em 22/06/2018. (BRASIL, 2018a).

\footnotetext{
UFPE - Universidade Federal de Pernambuco. Mestrado Profissional em Políticas Públicas. Recife PE -Brasil. 50670-901 - michelle.vfernandez@gmail.com. https://orcid.org/0000-0003-0224-0991.

* UNICAP - Universidade Católica de Pernambuco. Centro de Ciências Jurídicas. Recife - PE - Brasil. 50050-900 - josemwgomes@gmail.com. https://orcid.org/0000-0002-4003-856X.
} 
Cotidianamente, os mais diversos órgãos integrantes do Poder Judiciário são provocados a decidir questões litigiosas envolvendo políticas públicas, a eles submetidas de farta maneira por atores públicos e privados, em consequência do fenômeno sociopolítico da judicialização, podendo haver decisões passíveis de interferir em qualquer momento do respectivo ciclo, desde a formulação da agenda à execução de relevantes políticas governamentais nos três níveis federativos.

Em acórdão recente (REsp 1657156/RJ, Rel. Ministro Benedito Gonçalves, julgado em 25/04/2018, DJe 04/05/2018) (BRASIL, 2018), os Ministros integrantes da Primeira Seção do Superior Tribunal de Justiça (STJ), não apenas consolidaram entendimento no sentido de ser cabível a concessão judicial de medicamentos não incorporados em atos normativos do Sistema Único de Saúde (SUS), como também fixaram, sem participação dos entes do sistema único de saúde, quais seriam os critérios objetivos a serem preenchidos pelo solicitante para o deferimento de tal benefício: (i) comprovação, por meio de laudo médico fundamentado e circunstanciado expedido por médico que assiste o paciente, da imprescindibilidade ou necessidade do medicamento, assim como da ineficácia, para o tratamento da moléstia, dos fármacos fornecidos pelo SUS; (ii) incapacidade financeira de arcar com o custo do medicamento prescrito; (iii) existência de registro na Agência Nacional de Vigilância Sanitária (ANVISA) do medicamento.

Em outro precedente (REsp 1150392/SC, Rel. Ministro Sérgio Kukina, Primeira Turma, julgado em 13/09/2016, DJe 20/09/2016), a Primeira Turma Superior Tribunal de Justiça (STJ) julgou procedente pretensão do Ministério Público, contrária à implantação de conjunto habitacional às margens de curso d'água, em virtude de risco de degradação de bacia fluvial e de ausência de sistema de rede coletora de esgoto sanitário, destacando que a "omissão injustificada da administração em efetivar as políticas públicas constitucionalmente definidas e essenciais para a promoção da dignidade humana não deve ser assistida passivamente pelo Poder Judiciário". Desta maneira, em substituição às escolhas do administrador e dos legisladores, o colegiado daquela corte definiu que a política pública de proteção ambiental deveria prevalecer sobre a política pública habitacional do município.

Como compreender melhor quais os fatores que influenciam os membros do Poder Judiciário em suas decisões seletivas quanto à interferência - ou não nas políticas públicas governamentais? Este trabalho pretende revisar os principais modelos formais disponíveis na literatura - legalista, atitudinal e estratégico - para o entendimento do comportamento judicial, de modo a oferecer ao leitor/pesquisador as contribuições metodológicas para a compreensão do papel desempenhado pelo Judiciário, quando provocado a julgar litígios relacionados a políticas públicas. 
Judicialização, policy e modelos formais explicativos: uma proposta para compreender as decisóes judiciais em matéria de políticas públicas

\section{Judicialização das políticas públicas}

A progressiva constitucionalização que muitos direitos, principalmente os direitos sociais, passaram na década de 1980 no Brasil, associada aos desafios de implementação efetiva desses direitos por parte do Estado, fez com que tais questões, visando à sua efetivação, fossem cada vez mais submetidos ao crivo das instituições jurídicas.

De forma geral, podemos afirmar que os tribunais atuam politicamente em três dimensões: hobbesiana, smithiana e madisoniana (TAYLOR, 2007, p. 230). Estas dimensões representam, respectivamente, o impacto da atuação do Judiciário no monopólio da força pelo Estado, nas normas de funcionamento da economia e na relação entre Executivo, Legislativo e o próprio Judiciário. Quando tratamos de políticas públicas estamos nos referindo à dimensão madisoniana.

A trajetória peculiar das políticas de bem-estar em países periféricos, marcadas por sua incompletude ou, em alguns casos, por sua inexistência (FERNANDEZ, 2014; CARVALHO, 2008; FARIA, 1998; DRAIBE, 1990) faz com que o gozo dos direitos de cidadania e, principalmente, dos direitos sociais, não alcance uma grande porcentagem da população de países como o Brasil. Diante de uma relativa inoperância dos poderes Executivo e Legislativo na formulação e implementação de políticas públicas efetivas, torna-se cada vez mais relevante o papel do judiciário como arena para maximização da proteção dos direitos de cidadania.

No Brasil, a Constituição Federal (BRASIL, 2017) foi generosa na incorporação de direitos individuais e sociais, declarando sua universalidade e autoaplicação. Incorporou também referências a elementos abstratos, como a dignidade da pessoa humana, que favorecem as interpretações baseadas mais em princípios que no texto em si. A Constituição de 1988 seguiu o modelo europeu continental, com uma influência marcante dos textos constitucionais de Portugal e Espanha na sua formulação. (GONZALEZ, 2012).

Da mesma maneira, Couto e Arantes (2006) apontam que o desenho institucional da Constituição Federal de 1988 - tal como um produto do múltiplo arranjo de forças e de interesses conflitantes, característicos da respectiva assembléia nacional constituinte - apresenta demasiado conteúdo normativo referente a políticas públicas (policy) - em comparação a outros diplomas constitucionais - à razão de $30,5 \%$ de seus dispositivos.

Tal circunstância dificultaria a implantação de plataformas de governo, engessaria a agenda governamental e, via de consequência, construiria um cenário favorável à judicialização das questões políticas e à maior interferência judicial em assuntos de policy, "na medida em que o Judiciário [...] passa a ser mais acionado para controlar a constitucionalidade das leis e demais atos normativos [...] freqüentemente relativos a políticas públicas" (COUTO; ARANTES, 2006, p. 43-44). 
Nesse contexto, os órgãos judiciais passaram a atuar nos vazios institucionais deixados pelos poderes representativos. De acordo com Carvalho (2004, p. 117), estas alterações funcionais foram impulsionadas pelas mudanças interpretativas das escolas jurídicas, pela delegação e/ou omissão dos poderes Executivo e Legislativo, pelo aperfeiçoamento das instituições judiciárias - criação dos conselhos da magistratura, por exemplo -, pela crescente pressão da sociedade civil e, principalmente, pelo reconhecimento constitucional dos direitos fundamentais.

No Brasil, o Judiciário possui força considerável no que concerne à sua atuação frente as questões envolvendo políticas públicas, visto que "os agentes do Judiciário podem dar apoio a políticas que considerem relevantes ou adiar as consequências objetivas que a estas poderiam advir em razão do indeferimento de recursos interpostos" (ROCHA, 2010, p. 25).

O Judiciário tem sido solicitado com certa frequência, tanto com base na Constituição quanto na legislação infraconstitucional, para deliberar sobre políticas públicas contenciosas (TAYLOR, 2007). Assim, os tribunais podem redirecionar o curso das políticas públicas: influenciam os tipos de políticas que são implementadas, como são implementadas e julgam a legalidade dessas políticas dentro da sua visão das regras legais existentes e das normas e tradições vigentes.

Nos estudos sobre Judiciário no Brasil, estamos distantes de uma análise precisa do funcionamento desse poder (CARVALHO, 2004, p. 124), embora haja esse aumento notório na demanda pela atuação do judiciário, ainda existe uma dificuldade de traduzir o impacto das ações judiciais, em termos claros e objetivos, no processo das políticas públicas. Ainda se investiga pouco os processos pelos quais essa atuação ocorre. Ou seja, é preciso elaborar e tratar de responder questões acerca do impacto, dos mecanismos específicos, dos recursos, limites, incentivos e oportunidades vinculados ao poder judiciário, que influenciam ou até determinam o resultado de decisões relativas a políticas públicas.

É importante levar em consideração que o Judiciário pode ocupar uma posição importante de veto e deve ser considerado na estruturação do processo decisório (TAYLOR, 2007). Alguns estudos já realizados mostram que o Judiciário pode exercer poder de veto em determinados cenários envolvendo políticas públicas (RIBEIRO et. al., 2009).

Por outro lado, policy-makers do Executivo e Legislativo teriam uma capacidade considerável para ignorar ou resistir ativamente às decisões judiciais que consideram desagradáveis. Eles também teriam as ferramentas para enfraquecer a posição institucional e a autoridade do Judiciário de forma mais geral. Não é difícil encontrar exemplos históricos de ambas as estratégias [...] (VANBERG, 2015, p. 103). 


\section{Judicialização, policy e modelos formais explicativos: uma proposta para compreender as decisóes judiciais em matéria de politicas públicas}

Porém, ainda que se aceite que o Judiciário faz política, não se sabe ao certo qual é a política do Judiciário, qual o impacto dessa política e quais variáveis influenciam ou determinam o seu conteúdo.

Taylor (2007), observando o papel do Supremo Tribunal Federal (STJ) no processo das políticas públicas, afirma que existem quatro dimensões centrais que ajudam a analisar o efeito do Judiciário sobre as políticas públicas e a incorporá-lo ao estudo mais amplo sobre policy-making. São elas: a. Em que momento e de que maneira o Judiciário pode influenciar as políticas públicas? b. Quais as motivações do Judiciário na hora de tentar resolver disputas sobre políticas públicas? c. Como os atores externos ao Judiciário valem-se dele para atingir seus objetivos políticos? e, d. quais as conseqüências da intervenção do Judiciário nas políticas públicas?

Nas duas últimas décadas, os debates sobre os porquês, os comos e os efeitos do fenômeno sempre crescente da judicialização das políticas públicas foram marcados por argumentos polarizados e informações limitadas. Uma abordagem alternativa reconhece que a judicialização, desconsiderando o juízo de valor sobre o processo, é parte integrante do cenário democrático contemporâneo, algo a ser entendido em sua complexidade (BIEHL et al., 2018).

Para lograr este entendimento mais complexo de uma das vertentes de atuação política dos tribunais é necessário mapear as consequências da atuação do poder judiciário no processo das políticas públicas. Além disso, é fundamental levantar perguntas e hipóteses com relação à dinâmica decisória interna específica do poder Judiciário, bem como sua relação com os demais poderes no processo de tomada de decisão e execução de políticas. Seria pertinente tratar de observar se e como fatores como preferências políticas dos juízes, preferências de outros atores políticos, opinião pública e interação ou negociação em órgãos colegiados são relevantes para explicar padrões decisórios judiciais relativos às políticas públicas (TAYLOR, 2007).

Por um lado, percebe-se que cada vez mais os cidadãos demandam o Judiciário como ator para assegurar ou viabilizar a implementação das políticas públicas, visto que seu desenho institucional, pautado nos critérios de inamovibilidade, vitaliciedade e irredutibilidade de vencimentos, asseguram uma significativa independência dos juízes. Neste sentido, torna-se possível que o Judiciário contrarie os interesses governamentais, podendo resultar em "aperfeiçoamentos nas políticas públicas, tanto em termos econômicos como em termos de durabilidade destas políticas" (ROCHA, 2010, p. 29).

Devidamente provocado, considerando-se que a jurisdição é inerte, o Judiciário soluciona os casos concretos, garantindo aos cidadãos o acesso à políticas, seja na área de educação, saúde, habitação, segurança, etc. Por outro lado, esta atuação ativa do judiciário na implementação de políticas públicas sociais tem um impacto direto na atuação do Executivo: quando decisões são proferidas em favor de indivíduos, o custo da implementação dessas decisões vão recair sob os diferentes 
governos que ocupam o poder Executivo. Entender os dois lados dessa dinâmica, seus benefícios, malefícios e limitações é fundamental para entender e diagnosticar o fenômeno da judicialização das políticas públicas sociais.

\section{Modelos de análise para entender a atuação dos juízes}

Uma importante tarefa para desvendar e diagnosticar o fenômeno da judicialização das políticas sociais é entender como são tomadas as decisões que impactam na implementação das políticas públicas. Enquanto as decisões no âmbito Legislativo costumam ser compartilhadas por amplos colegiados, formados por representantes eleitos distribuídos entre os diversos partidos políticos, no Executivo e no Judiciário o processo de tomada de decisão tende a ser centrado no indivíduo ou dividido em pequenos colegiados e hierarquizado.

Assim, observando o Judiciário, em um primeiro momento o juiz que toma estas decisões aparece como um decisor técnico, sem paixões, afastado do processo político. Por vezes, omite-se a função política do decisor para vê-lo como um intelectual fazendo a interpretação isenta do caso em questão, com base nos argumentos apresentados (GONZALEZ, 2012). Ainda se sabe pouco sobre as idéias de um grupo pequeno de pessoas que tem o poder de modificar a vida da população de todo o país com suas decisões, ou seja, sobre juízes, desembargadores e ministros dos tribunais superiores.

Uma eficiente maneira de se buscar a compreensão através de enfoques empíricos do funcionamento das instituições estatais - notadamente a análise do comportamento decisório das instituições judiciais - consiste na utilização dos diversos modelos formais disponibilizados pela literatura. Tais modelos fazem a transição entre o comportamento descrito e aquele esperado em teoria normativa, compreendendo os fenômenos concretos objeto de pesquisa, bem como sendo condutores de relevantes hipóteses a serem testadas e fontes de variáveis extraídas das diversas percepções possíveis acerca do descrito fenômeno.

[A] causalidade é uma propriedade de um modelo hipotético. Um modelo totalmente articulado dos fenômenos estudados precisamente define estados hipotéticos ou contrafactuais. [...] Um modelo é um conjunto de mundos possíveis contrafactuais construídos sob algumas regras. As regras podem ser as leis da física, as consequências da maximização da utilidade, ou as normas que regem as interações sociais, para tomar apenas três dos muitos exemplos possíveis (HECKMAN, 2005, p. 2). 


\section{Judicialização, policy e modelos formais explicativos: uma proposta para compreender as decisóes judiciais em matéria de politicas püblicas}

Um modelo causal em pesquisas sociais e sociais aplicadas articula logicamente variáveis, premissas e equações, que são, na verdade, representações numéricas, ordinais ou categóricas de aspectos de um fato ou de um fenômeno, utilizada como ferramenta para capturar a essência de um comportamento e explicar os processos intrínsecos à sua ocorrência (NAGEL; NEEF, 1977)

Através de um modelo, um dado pesquisador se resguarda de um arsenal de ferramentas metodológicas dirigidas a conferir as múltiplas explicações que a teoria pretende dar ao fenômeno ora submetido ao crivo científico, buscando verificar, quantitativa e/ou qualitativamente, a presença - ou não - de associações, interações, influências ou relações de causalidade, entre o resultado que se quer entender e a presença, ou ausência, no conjunto de casos estudados, de determinadas informações - variáveis - sobre o fato estudado. Em um modelo formal de pesquisa as representações de um fato ou de um fenômeno são materializadas numa ferramenta útil a captar o conteúdo de um comportamento e explicar os processos intrínsecos à sua ocorrência (SEGAL; SPAETH, 2002).

Em virtude da dificuldade - quiçá impossibilidade - de se apurar, com sinceridade, veracidade e objetividade, o que pensam os atores judiciais no momento da tomada de decisões acerca dos conflitos que lhe são submetidos - judicializados-, os referidos modelos formais, cada qual a seu modo, confrontam qualitativa e/ou quantitativamente os produtos das decisões judiciais com informações extraídas das hipóteses originadas em cada modelo.

Os concorrentes modelos de comportamento judicial diferem sobre uma série de questões, que vão desde o lugar do direito à influência da opinião pública sobre o julgamento da Suprema Corte. Grande parte dos estudiosos desta área centra-se nestas diferenças, a exemplo de estudiosos que defendem posições específicas e realizam pesquisas sobre pontos de discordância entre os modelos (BAUM, 2009, p. 9).

Existem diversas teorias positivas - isto é, descritivas dos fatos como são, em distinção às teorias meramente normativas, que se limitam a afirmar como os fatos deveriam ser - do comportamento judicial, cuja razão de existir é explicar as decisões judiciais sob diversos prismas, sejam jurídicos, econômicos, psicológicos, fenomenológicos, dentre muitos aqueles disponíveis.

A compreensão das decisões judiciais, em sua acepção comportamental, é realizada pelo emprego de modelos formais de pesquisa dos mais diversos matizes atitudinais, estratégicas, organizacionais, culturais, históricas, dentre outras - sendo os modelos legalista, atitudinal e estratégico os mais presentes na literatura sobre comportamento judicial e sobre judicial politics (POSNER, 2008). Os modelos mencionados têm em comum a apresentação, individual ou conjunta, de elementos 
que se propõem a explicar os motivos pelos quais as decisões dos órgãos judiciários são tomadas. Estes motivos devem ser confirmados através de testes empíricos aplicados sobre dados relacionados às referidas decisões (GOMES NETO, 2018, p. 24).

Em primeiro lugar, para um modelo legalista - ou jurídico - os julgadores escolhem entre os resultados para os casos e/ou posições doutrinárias alternativas, baseados nos respectivos méritos jurídicos (BAUM, 2009), ou seja, espera-se que o comportamento judicial seja pautado pela maneira como o órgão julgador individual ou coletivo - reage às fontes do direito - a legislação, os precedentes, os costumes jurídicos, os princípios, a literatura jurídica etc.

$\mathrm{O}$ uso deste modelo não significa necessariamente que o pesquisador entende serem os juízes legalistas: na verdade, busca-se compreender o grau de influência dos fatores estritamente jurídicos na estabilidade ou na variação das decisões judiciais, percebidos isoladamente - ainda que artificialmente - de outros fatores que possam influenciar no contexto decisório.

Suas hipóteses afirmam que fatores legalistas - estritamente jurídicos - são relevantes para a tomada de decisão, sendo testadas variáveis relacionadas aos fundamentos jurídicos alegados pelos atores requerentes, aos assuntos tratados nos litígios - v.g., família, tributário, trabalhista, políticas públicas-, à natureza da legislação supostamente violada - constitucional, federal, estadual e municipal -, à fonte do direito utilizada na decisão - legislação, doutrina, princípios e jurisprudência -, dentre outros.

Utilizando-se um modelo legalista, Taylor (2008) identificou que o assunto tratado nas ações diretas de inconstitucionalidade influenciava nas chances de deferimento, ou não, de liminares, de forma monocrática ou colegiada, pelos Ministros do Supremo Tribunal Federal (STF); do mesmo modo, verificou que a natureza da legislação impugnada - federal, estadual ou municipal - exercia uma influência muito sutil nas chances de deferimento da liminar requerida.

Por sua vez, um modelo atitudinal parte do pressuposto de que as decisões judiciais são consequências das preferências - atitudes - individuais de cada julgador, construídas ao longo de sua trajetória até o momento em que decidir cada caso. Neste sentido, o presente decisional de cada juiz é construído, par e passo, pela soma de suas experiências pretéritas.

As preferências políticas de cada juiz refletem-se nos resultados e nos fundamentos de cada julgamento, pois num modelo atitudinal puro, os juízes apenas desejariam produzir boas políticas públicas, pelo que escolheriam entre alternativas, com base em méritos de cada política pública que melhor represente suas preferências (BAUM, 2009).

Assim, as hipóteses construídas a partir deste modelo entendem que as características dos julgadores, que melhor refletem suas preferências (ideologia, 


\section{Judicialização, policy e modelos formais explicativos: uma proposta para compreender as decisóes judiciais em matéria de politicas püblicas}

religião, gênero, condutas ativistas ou conservadoras, manifestações públicas, correntes de pensamento etc.), estariam refletidas nas características de suas decisões, não necessariamente de forma simétrica.

Embora, tradicionalmente, os modelos atitudinais associem preferências políticas dos julgadores a eventuais vínculos político-partidários, seja num passado de militância, seja pelo processo político de indicação e confirmação de membro de corte suprema, isto não afasta outras informações relevantes à indicação de preferências, a exemplo de dados sobre a carreira jurídica desempenhada ou sobre a formação acadêmica do juiz. Portanto, o modelo atitudinal parte do princípio de que as decisões judiciais podem ser explicadas a partir das preferências políticas construídas a partir de atitudes e valores. Estes atributos individuais são trazidos pelos julgadores para análise dos conflitos, inferindo tais preferências a partir de variáveis indiretas (GOMES NETO, 2012).

Oliveira (2012), utilizando a composição do Supremo Tribunal Federal como proxy atitudinal - em sete períodos históricos, ocorridos entre 1999 e 2006 -, verificou a existência de uma associação entre a variação sucessiva na composição do Tribunal, entendida como a distribuição percentual de seus membros quanto à origem nas carreiras jurídicas - advogado, ministério público ou juiz de carreira, e a variação no resultado dos julgamentos em cada período testado.

Por fim, para o modelo estratégico, as preferências individuais dos julgadores, embora presentes, ficam em segundo plano, constrangidas a partir da antecipação das consequências possíveis dos julgados - econômicas, sociais e políticas - e das expectativas de outros atores, ou seja, demais membros da corte, opinião pública, imprensa, partidos políticos, atores requerentes etc. O modelo estratégico do comportamento judicial, que também pode ser chamado de modelo político-positivo, toma como ponto de partida a ideia de que os juízes nem sempre tomariam determinada decisão se não estivessem preocupados com a reação que seus votos poderiam causar na opinião de outros juízes, nos legisladores ou no próprio público.

Assim, de acordo com este modelo, os decisores organizam a análise da estratégia política através dos pontos de pressão dos grupos de interesses, mediante o emprego dos métodos da teoria dos jogos, e/ou levando em consideração embates históricos entre os Judiciários e os demais Poderes de governo (GOMES NETO, 2012).

O cálculo decisório a ser apurado em modelo estratégico sobre o comportamento judicial leva em conta que os juízes constrangem suas preferências pessoais a partir de racionalidades estratégicas sobre as prováveis reações de outros atores (EPSTEIN; KNIGHT, 1998). Em um modelo estratégico órgãos julgadores decidem sobre políticas públicas, mas definem quais seriam as boas políticas públicas, principalmente, em função das respectivas consequências para sua corte e para o Estado 
como um todo, bem como em função das expectativas que lhes são apresentadas (BAUM, 2009).

Analisando variáveis estratégicas em seu estudo sobre a concessão de liminares pelo Supremo Tribunal Federal (STJ) em ações diretas de inconstitucionalidade, Taylor (2008) verificou que alguns atores (requerentes) possuíam maior chance de obter decisões favoráveis em relação a outros atores, havendo uma grande variação de chances entre os atores legitimados a instaurar a revisão judicial concentrada, confirmando a hipótese testada no referido estudo, de que no cenário de judicialização da política, importa para o exercício efetivo do controle judicial a natureza e as expectativas de quem provoca a interferência judicial no conflito politicamente relevante.

Para observar e analisar o comportamento do judiciário com relação às políticas sociais optamos por considerar o modelo atitudinal em detrimento das demais opções teóricas. O Poder Judiciário tem cada vez mais sido objeto de análise, porém o pensamento e identidade ideológica de seus membros concretamente identificados desde um ponto de vista de análise acadêmica ainda são desconhecidos (GONZALEZ, 2012). Partindo da premissa de que no modelo atitudinal as decisões judiciais podem ser explicadas a partir das preferências dos juízes construídas a partir de atitudes e valores, a escolha por este modelo se dá pelo fato da importância dada aos direitos sociais estar intimamente vinculada à concepção pessoal do indivíduo sobre valores e crenças. Estas características intrínsecas aos indivíduos podem se ver refletidas nas suas ações, no caso do Judiciário, nas decisões proferidas por seus atores - juízes, desembargadores e ministros. Assim, atributos individuais são trazidos pelos julgadores para a análise dos conflitos.

Um dos pontos centrais a ser considerado para a escolha deste modelo é o peso a ser dado ao processo de socialização na formação de valores e preferências dos juízes, em relação a variáveis contextuais e normas institucionais. O outro aspecto que dever ser levado em consideração é se estas preferências podem ser consideradas estáveis ao longo do tempo, servindo como preditor de decisões futuras (GONZALEZ, 2012).

\section{Judicializando a Policy: possibilidade de aplicação dos modelos explicativos à análise de decisões em temas de políticas públicas}

Alguns elementos básicos inerentes à análise das políticas públicas são pessoas e organizações, com seus interesses, competências e comportamento variados (SECCHI, 2010). Assim sendo, as políticas públicas são estabelecidas por um emaranhado de atores e de interações entre eles. São considerados atores todos indivíduos, grupos ou organizações que desempenham um papel na arena política. Estes 
Judicialização, policy e modelos formais explicativos: uma proposta para compreender as decisóes judiciais em matéria de políticas públicas

influenciam o processo político e possuem comportamentos e interesses que variam conforme os papéis que interpretam no cenário política.

Segundo Taylor (2007), os tribunais podem ser um ator relevante na relação entre os poderes Executivo, Legislativo e Judiciário. Isso porque, entre outros fatores, eles geram impactos na formulação de políticas públicas pelo Executivo e pelo Legislativo e na implementação dessas políticas (FERNANDEZ; SANTIAGO; PEDROSA, 2018). Assim, o Judiciário, junto a governadores, prefeitos e burocracias estatais, tem um impacto significativo nas políticas públicas. Os tribunais ampliam o leque de atores que podem influenciar nas políticas, nas diferentes fases do ciclo de políticas públicas ${ }^{1}$ (TAYLOR, 2007, p. 234). Da definição da agenda, passando pela formulação e processo decisório e chegando na implementação das políticas, em todas e em cada uma destas fases o Poder Judiciário pode atuar diretamente.

A definição da agenda consiste em trazer para a esfera pública temas que eram considerados problemas por indivíduos ou grupos específicos. A agenda é uma série de questões ou problemas aos quais os atores políticos passam a dar importância em um determinado momento (KINGDON, 1995). A definição da agenda consiste em reconhecer que um determinado problema é uma questão pública e deve ser tratado pelos agentes políticos (WU et al., 2004). Portanto, nesta fase do ciclo das políticas públicas, as demandas de diversos grupos podem ser traduzidas em pontos que os governos considerem para a ação, ou seja, para traduzir em políticas públicas.

Fazem parte da definição da agenda agentes estatais e sociais. Entre os agentes estatais temos os eleitos e os nomeados. Os membros do judiciário aparecem no grupo dos agentes estatais nomeados que incidem na formação da agenda. Nessa fase do processo das políticas públicas, os juízes assumem um papel importante propondo novos temas e pressionando a construção da agenda dos outros poderes através da construção da sua própria pauta.

$\mathrm{Na}$ formulação e processo decisório são criadas possíveis alternativas para responder a um problema coletivo e escolhida a melhor alternativa entres todas criadas. Essa fase do ciclo das políticas públicas é bastante conflituosa porque nela é tomada a decisão sobre a política que será escolhida. Entre um leque de opções, que traduzem diferentes posições de poder, apenas uma será eleita para transformar-se em política pública.

1 O ciclo de políticas públicas é um referencial teórico para a análise das políticas públicas. Esta abordagem serviu à necessidade de organizar e sistematizar um crescente corpo de literatura e pesquisa que começou a ser desenvolvido entre 1960 e 1970. Hoje, a diferenciação entre a definição da agenda, formulação de políticas, tomada de decisão, implementação e avaliação tornou-se a forma convencional para descrever a cronologia de um processo de política pública (TREVISAN; VAN BELLEN, 2008). 
Os dirigentes políticos - ministros e secretários - e os legisladores são os formuladores de políticas públicas por excelência (WU et al., 2004). Os agentes do poder judiciário também podem atuar como policy-makers. À medida que revisam e, inclusive, modificam projetos aprovados pelo legislativo e medidas adotadas pelo executivo, estes atores estão criando e tomando decisões sobre as políticas públicas que serão implementadas.

A implementação é a fase da ação no ciclo de políticas públicas. Nesta fase as regras, rotinas e processos sociais são transformados em ações práticas. Até este momento, a política apresenta-se de forma discursiva. Somente a partir da implementação que as intenções políticas se transformam em fatos concretos, em realidade palpável. Porém, é importante ter claro que na implementação é possível se deparar com mais do que problemas técnicos ou administrativos. Há, na verdade, grandes chances de que se encontre um emaranhado de elementos políticos que podem frustrar os planejamentos previamente estabelecidos (PRESSMAN; WILDAVSKY, 1973). Muitas vezes, é nesta falha que o Judiciário atua. Assim, na tentativa de garantir direitos, o Judiciário interfere na implementação de políticas públicas pelos governos.

Assim, pensando na diversidade da atuação do Judiciário em temas de políticas públicas, como os modelos formais poderiam auxiliar na resolução de questões de pesquisa neste campo? A partir da descrição de uma possível atuação do Judiciário em cada uma das fases do ciclo de políticas públicas, no Quadro 1 propomos algumas hipóteses relacionando-as aos diferentes modelos explicativos de atuação do judiciário apresentados na seção anterior. Este exercício visa apontar possibilidades para os pesquisadores e estudiosos que tenham interesse em pensar a relação do poder judiciário com as políticas públicas. 
Judicialização, policy e modelos formais explicativos: uma proposta para compreender as decisóes judiciais em matéria de politicas públicas

Quadro 1: Modelos formais explicativos e hipóteses testáveis

\begin{tabular}{|c|l|}
\hline Modelo & \multicolumn{1}{c|}{ Hipóteses testáveis (exemplos) } \\
\hline Legalista & $\begin{array}{l}\text { 1. A interferência judicial na política pública tende a ser menor quando } \\
\text { sua agenda estiver exaustivamente pré-definida em legislação editada pelo } \\
\text { Poder Legislativo; } \\
\text { 2. A interferência judicial é maior em políticas públicas previstas em atos } \\
\text { normativos estaduais que em atos de competência federal; } \\
\text { 3. A interferência judicial é maior quanto a políticas públicas gerais } \\
\text { e abstratas (previstas na legislação) e menor quanto a políticas públicas } \\
\text { (previstas na legislação) concretas. }\end{array}$ \\
\hline Atitudinal & $\begin{array}{l}\text { 1. O alinhamento ideológico do juiz (liberal ou conservador) está associado } \\
\text { à variação nas chances de interferência judicial em políticas públicas; } \\
\text { 2. Juízes associados a partidos políticos de esquerda possuem maiores } \\
\text { chances de interferir em políticas públicas envolvendo direitos sociais; } \\
\text { 3. A classe econômica de origem do juiz está associada à variação das } \\
\text { chances de sua interferência em políticas públicas; } \\
\text { 4. Opiniões pretéritas dos juízes estariam associadas à variação atual nas } \\
\text { suas decisões em temas de política pública. }\end{array}$ \\
\hline Estratégico & $\begin{array}{l}\text { 1. Litigantes individuais possuem maiores chances de obter interferência } \\
\text { judicial em políticas públicas que litigantes coletivos (ministério público, } \\
\text { associações, sindicatos etc.); } \\
\text { 2. Em períodos associados a crises políticas e/ou econômicas são menores } \\
\text { as chances de interferência judicial em políticas públicas; } \\
\text { 3. Políticas públicas de saúde possuem maiores chances de interferência } \\
\text { judicial que políticas públicas de educação fundamental; } \\
\text { 4. Há maiores chances de interferência judicial em políticas públicas com } \\
\text { forte apelo popular ou pressão da opinião pública. }\end{array}$ \\
\hline
\end{tabular}

Fonte: elaboração dos autores

A partir das hipóteses sugeridas no Quadro 1 e dos modelos explicativos já apresentados, apresenta-se abaixo aplicações ilustrativas de análise da atuação do judiciário em diferentes fases do ciclo das políticas públicas. A apresentação desses exemplos demonstra o rico potencial investigativo que possui o estudo conjunto desses dois campos, o poder judiciário e as políticas públicas:

1. Em uma pesquisa hipotética, um investigador poderia aplicar um modelo legalista para testar se a variação no grau de abstração e de discricionariedade previstas na legislação seria - ou não - incentivo à existência de 
decisões judiciais, que, em situações concretas e específicas, tenham o escopo de substituir a vontade do administrador ou do legislador eleito, v.g., na definição de agendas ou na construção de rotinas ou de procedimentos a serem obedecidos pelos agentes e/ou pelos usuários de serviços públicos;

2. Em um outro estudo hipotético, um cientista - social, político ou jurídico -, através de entrevistas estruturadas - pesquisa qualitativa -, poderia obter de um juiz ou de desembargador informações sobre a sua trajetória de vida, bem como a respeito de suas preferências - atitudes- em determinados temas levados à resolução judicial, de modo a explicar uma postura rígida ou flexível do julgador frente a tarefa de definir os rumos da formulação de uma política pública;

3. Como último exemplo, uma pesquisa empírica, mediante o uso de um modelo estratégico, poderia analisar se a variação no nível de popularidade do incumbente eleito para um cargo majoritário executivo - presidente, governador ou prefeito - estaria associada às chances de maior ou menor intervenção do Poder Judiciário na implementação de políticas públicas, com vistas a testar se as expectativas da população local ou dos eleitores importaria para a formação das decisões judiciais.

Tomando como ponto de partida as possíveis hipóteses apresentadas e os exemplos de pesquisa desenhados anteriormente, no Quadro 2 estão expressas algumas possíveis variáveis independentes ${ }^{2}$ pensadas a partir dos três modelos explicativos propostos neste manuscrito para analisar o comportamento do judiciário em temas de políticas públicas.

2 Variável que representa o fator causal de uma teoria (KING, KEOHANE e VERBA, 1994). 
Judicialização, policy e modelos formais explicativos: uma proposta para compreender as decisóes judiciais em matéria de politicas públicas

Quadro 2: Modelos formais explicativos e respectivas variáveis independentes

\begin{tabular}{|c|c|}
\hline Modelo & Variáveis independentes testáveis \\
\hline Legalista & $\begin{array}{l}\text { 1. Natureza da legislação; } \\
\text { 2. Tema objeto da política pública; } \\
\text { 3. Previsão concreta ou abstrata da política pública; } \\
\text { 4. Obediência a precedentes jurisprudenciais; } \\
\text { 5. Fundamentação em princípios constitucionais gerais e abstratos. }\end{array}$ \\
\hline Atitudinal & $\begin{array}{l}\text { 1. Alinhamento ideológico (liberal ou conservador); } \\
\text { 2. Militância partidária prévia; } \\
\text { 3. Indicação partidária (STF); } \\
\text { 4. Identidade de preferências entre indicante e julgador; } \\
\text { 5. Classe econômica de origem do juiz; } \\
\text { 6. Opiniões prévias do julgador. }\end{array}$ \\
\hline Estratégico & $\begin{array}{l}\text { 1. Natureza das partes envolvidas no litígio; } \\
\text { 2. Opinião pública; } \\
\text { 3. Expectativas dos demais julgadores; } \\
\text { 4. Condições econômicas; } \\
\text { 5. Distância do período eleitoral (tempo); } \\
\text { 6. Custo envolvido na política pública. }\end{array}$ \\
\hline
\end{tabular}

Fonte: elaboração dos autores

Desenhos de pesquisa, sejam quantitativos e/ou qualitativos, são capazes de operar maneiras eficientes e adequadas de testar hipóteses derivadas de modelos explicativos, dentre as quais as apontadas nos exemplos acima descritos. Nos estudos envolvendo o Poder Judiciário e as políticas públicas, a verificação empírica da existência de relações, correlações ou associações entre a presença de tais variáveis - ou a variação em seus valores - e o resultado a ser estudado, in casu, as decisões tomadas pelos juízes quanto à sua interferência em qualquer dos sucessivos momentos do referido ciclo de políticas públicas certamente trará achados de pesquisa relevantes.

Tais ferramentas descritas ao longo deste trabalho auxiliam os investigadores a compreender de forma mais aprofundada as nuances do comportamento judicial, nos cenários de interseção entre a judicialização da política e o campo de políticas públicas, fornecendo base empírica para o entendimento do comportamento judicial, bem como das consequências de suas escolhas sobre as etapas do ciclo de políticas públicas. 


\section{Conclusões}

Os apontados modelos explicativos do comportamento judicial não nos trazem respostas prontas para a indagação quanto ao que leva o Poder Judiciário a interferir em políticas públicas, mas, do contrário, apontam caminhos paralelos e complementares a serem trilhados pelos pesquisadores, que desejem avançar nas respostas às múltiplas questões relacionadas a um objeto complexo.

Esses caminhos vão, aos poucos, elucidando como e porque as instituições judiciais atuam, diante de provocações para resolver litígios vinculados a políticas públicas, pondo o julgador diante de interesses majoritários e contra-majoritários, bem como diante de agendas postas por representantes eleitos, nas searas executivas e legislativas. Entre as escolhas possíveis - interferir, não interferir ou simplesmente silenciar - podem estar presentes fatores provavelmente relacionados aos modelos apresentados aqui, descortinando relevantes detalhes da equação decisória judicial nos temas de políticas públicas.

Deixamos, portanto, diversos caminhos em aberto para que pesquisadores que se interessem pela junção entre o Judiciário e políticas públicas possam percorrer. Um pesquisador inquieto pode optar, por um lado, por uma dos modelos explicativos para entender o papel dos julgadores no universo das políticas públicas; e, por outro lado, pode ainda escolher qual fase do ciclo das políticas públicas será tomada como unidade de análise para sua investigação: a formação da agenda, a formulação e tomada de decisão ou a implementação de políticas públicas.

\section{JUDICIALIZATION, POLICY AND EXPLANATORY FORMAL MODELS: \\ A PROPOSAL FOR UNDERSTANDING JUDICIAL DECISIONS ABOUT PUBLIC POLICIES}

ABSTRACT: This article aims to present an analysis proposal of the judiciary's performance in public policies. In order to do that, we point out the different models of analysis found in the literature that try to explain the performance of the judiciary, on the one hand, and present the possible locus of action of this political actor in the cycle of public policies, on the other. Therefore, we will try to indicate ways to answer the following question: how can we better understand which factors influence the members of the Judiciary in their selective decisions about the interference - or not - in government public policies?

KE YWORDS: Judiciary. Public policy. Policy of legalization. Explanatory models. 
Judicialização, policy e modelos formais explicativos: uma proposta para compreender as decisóes judiciais em matéria de politicas públicas

\title{
JUdiCIALIZACIÓN, POLICY Y MODELOS FORMALES EXPLICATIVOS: UNA PROPUESTA PARA COMPRENDER LAS DECISIONES JUDICIALES EN MATERIA DE POLÍTICAS PÚBLICAS
}

\begin{abstract}
RESUMEN: Este artículo tiene como objetivo presentar una propuesta de análisis de la actuación del poder judicial en las políticas públicas. De esta forma, hemos señalado, por un lado, los diferentes modelos de análisis en la literatura que tratan de explicar el papel del poder judicial, y de otro presentamos los posibles locus de actuación de este actor político en el ciclo de políticas públicas. Por consiguiente, buscaremos indicar caminos para responder a la siguiente cuestión: ¿cómo comprender mejor que factores influyen en los miembros del Poder Judicial en sus decisiones selectivas en cuanto a la interferencia - o no - en las políticas públicas gubernamentales?
\end{abstract}

PALABRAS CLAVE: Poder Judicial. Políticas públicas. Judicialización de la política. Modelos explicativos.

\section{REFERÊNCIAS}

BAUM, Lawrence. The Supreme Court. Ohio: CQ Press, 2009.

BIEHL, J., SOCAL, M., GAURI, V., DINIZ, D., MEDEIROS, M., RODON, G., AMON, J. Judicialization 2.0: Understanding right-to-health ligitation in the real time. Global Public Health, 2018.

BRASIL. Superior Tribunal de Justiça STJ. AgRg no RECURSO ESPECIAL: AgRg no REsp 1215252 RN 2010/0177717-7. 13 de agosto de 2016. 2016. Disponível em: <https://stj. jusbrasil.com.br/jurisprudencia/455629069/agrg-no-recurso-especial-agrg-no-resp-1215252rn-2010-0177717-7>. Acessado em 29 nov. 2018.

BRASIL. Constituição da República Federativa do Brasil de 1988. Tribunal Regional do Trabalho da $2^{\text {a }}$ Região. Atualizada até a EC n 99, de 14/12/2017. Diário Oficial da União - DOU, 15 de dezembro de 2017. Disponível em: <http://www.trtsp.jus.br/legislacao/ constituicao-federal-emendas $>$. Acessado em 29 nov. 2018.

BRASIL. Superior Tribunal de Justiça - STJ. RECURSO ESPECIAL: REsp 1657156 RJ 2017/0025629-7 - Inteiro Teor. 4 de maio de 2018. 2018. Disponível em: <https://stj.jusbrasil. com.br/jurisprudencia/574252474/recurso-especial-resp-1657156-rj-2017-0025629-7/inteiroteor-574252509>. Acessado em 29 nov. 2018. 
BRASIL. Superior Tribunal de Justiça - STJ. ARE 903241 RECURSO EXTRAORDINÁRIO COM AGRAVO. MIN. EDSON FACHIN. 22 de junho de 2018. 2018a. Disponível em: $<$ http://portal.stf.jus.br/processos/detalhe.asp?incidente $=4815202>$. Acessado em: 29 nov. 2018.

CARVALHO, E. Em busca da judicialização da política no Brasil: apontamentos para uma nova abordagem. Revista Sociologia e Política, Curitiba, 23, 2004, p. 115-126.

CARVALHO, J. M. Cidadania no Brasil: o longo caminho. Rio de Janeiro: Civilização Brasileira, 2008.

COUTO, C. e ARANTES, R. Constituição, governo e democracia no Brasil. Revista Brasileira de Ciências Sociais, vol. 21, nº 61, 2006, p. 41-62.

DRAIBE, S. As Políticas sociais Brasileiras: diagnóstico e perspectivas. In: IPEA, IPLAN. Prioridades de Políticas Públicas para a Década de 90. Brasília: IPEA/IPLAN, 1990.

EPSTEIN, Lee e KNIGHT, Jack. The Choices Justices Make. Washington: Congressional Quarterly, 1998.

FARIA, C. A. P. Uma genealogia das teorias e modelos do Estado de Bem-Estar Social. Boletim Bibliográfico de Ciências Sociais, n. 46, 2o, p. 41-65, 1998.

FERNANDEZ, M. V. La ciudadanía incompleta: Derechos económicos y sociales en la periferia urbana de Brasil. Salamanca: Ediciones Universidad de Salamanca, 2014.

FERNANDEZ, M. V., SANTIAGO, F. e PEDROSA, M. O embate Executivo-Judiciário no ciclo de políticas públicas: a judicialização das políticas de saúde. Anais do $\mathbf{5 4}^{\circ}$ Congresso Internacional de Americanistas. Salamanca, 2018.

GOMES NETO, José Mário Wanderley. As várias faces de um leviathan togado: um espectro das abordagens teóricas em ciência política acerca do fenômeno da judicial politics. Mnemonise Revista, v. 3, 2012, p. 107-120.

. Pretores estratégicos: Por que o Judiciário decide a favor do Poder Executivo e contra suas próprias decisões? São Paulo: Novas Edições Acadêmicas, 2018.

GONZALEZ, R. Análise de um modelo atitudinal do comportamento dos membros dos tribunais superiores no Brasil. Anais do VIII Encontro da Associação Brasileira de Ciência Política, Gramado, 2012.

HECKMAN, J. J.. The scientific model of causality. Sociological Methodology, Vol. 35, 2005.

KING, Gary, KEOHANE, Robert O. y VERBA, Sidney. Designing Social Inquiry: Scientific Inference in Qualitative Research. Princeton: Princeton University Press, 1994.

KINGDON, J. Como chega a hora de uma ideia? In SARAIVA, E. e FERRAREZI, E. (Eds.), Políticas Públicas - coletânea. v. 1, Brasília: ENAP, 2006, p. 219-224. 


\section{Judicialização, policy e modelos formais explicativos: uma proposta para}

compreender as decisóes judiciais em matéria de politicas públicas

NAGEL, Stuart e NEEF, Marian. Models of judicial decision-making. In JOHNSON, G. W. (ed.) American Political Science Research Guide, vol.1. New York: IFI/Plenum Data Company, 1977.

OLIVEIRA, F. L. Supremo relator: processo decisório e mudanças na composição do STF nos governos FHC e LULA. Revista Brasileira de Ciências Sociais, vol. 27, n.80, 2012, p.89-115.

POSNER, Richard A. How judges think. Cambridge: Harvard University Press, 2008.

PRESSMAN, J. e WILDAVSKY, A. Implementation: how great expectations in Washington are dashed in Oakland or, why it's amazing that federal programs work at all, this being a saga of the Economic Development Administration as told by two sympathetic observers who seek to build morals on a foundation of ruined hopes. Berkeley: University of California Press, 1973.

RIBEIRO, L.; ARGUELHES, D. e PEIXOTO, V. Processo decisório, judiciário e políticas públicas: Levando a decisão judicial a sério. Workshop de Pesquisadores da FGV/ DIREITO. Rio de Janeiro, 2009.

ROCHA, A. F. Judiciário e Políticas Públicas: a concretização dos direitos fundamentaissociais. Revista da SJRJ, Rio de Janeiro, n. 27, 2010, p. 19-32.

SECCHI, Leonardo. Políticas públicas: conceitos, esquemas de análise, casos práticos. São Paulo, Cengage Learning, 2010.

SEGAL, J. A. e SPAETH, H. J. The Supreme Court and the attitudinal model revisited. New York: Cambridge University Press, 2002.

TAYLOR, M. O Judiciário e as Políticas Públicas no Brasil. Dados - Revista Brasileira de Ciências Sociais, Rio de Janeiro, v. 50, nº 2, 2007, p. 229-257.

.Judging policy: courts and policy reform in democratic Brazil. Stanford: Stanford University Press, 2008.

TREVISAN, Andrei Pittol e VAN BELLEN, Hans Michael. Avaliação de políticas públicas: uma revisão teórica de um campo em construção. Revista de Administração Pública, 3, 42, 2008, p. 529-550.

VANBERG, G. Constitutional Courts in Comparative Perspective: A Theoretical Assessment. Annual Review of Political Science, v. 18, 2015, p. 10.1-10.19.

WU, X., RAMESH, M., HOWLETT, M. e FRITZEN, S. Guia de políticas pública: gerenciando processos. Brasília: ENAP, 2014.

Recebido em 13/08/2018.

Aprovado em 09/11/2018. 
